ISAHP 2001, Berne, Switzerland, August 2-4, 2001

\title{
AHP AS A TOOL FOR CONFLICT RESOLUTION
}

\author{
Edgar E. Osuna and Ernesto E. Coello \\ Centro de Producción e Innovación Tecnológica \\ Instituto de Estudios Superiores de Administración (IESA) \\ Avenida IESA, San Bernardino, Caracas - Venezuela \\ eosuna@iesa.edu.ve \\ ecoello@iesa.edu.ve
}

Keywords: AHP applications; conflict resolution; negotiation

Summary: The use of AHP is proposed for the resolution of conflicts that develop in decisions when these are made by two or more actors who represent different interests, particularly when the options available are compared in terms of multiple criteria. A real case of negotiation is presented in which the ex-post use of AHP proved its potential as an aid for the resolution of this type of conflicts.

\section{Introduction}

Any decision is a conflict by itself, and decision-making aids are nothing else but conflict resolution aids. It is not surprising then to see AHP as a technique with great potential for being used by negotiators, arbitrators and mediators in a wide class of conflictive situations.

Mechanisms for conflict resolution are required when there are two parties in a conflict (or preconflict) situation, which is different to the case of a 'group' of two parties in an ordinary decision-making process. It is assumed that in the later the parties have common goals though different value schemes, whilst in the former they have opposing (conflicting) objectives.

Arbitration procedures usually lead to the acceptance of either one of the two proposals presented by the parties with no possibility of some 'intermediate' solution. It is clear that this is perceived as a risky situation for both parties because of the implicit 'great loss' represented by the winning of the opponent proposal. The mediation or negotiation instead has the purpose of 'negotiating' this risk by producing some proposal satisfactory to both parts, which will represent a 'small loss with certainty' as compared to the 'great loss with some degree of probability' (possibility of a great loss) implied by the arbitration. This points to favour the use of bargaining or negotiation for the decision process.

The key for a successful mediation or negotiation is the achievement of a solution with no pains to either party, and in short times; this is no easy to attain and the process is tied up because of lack of information with regard to the other party values. The only way to continue the process is to neutralise this asymmetry of information, and we contend that AHP is a sound technique for doing it.

\section{The problem}

We assume the existence of a multiple-dimensions decision to be made and two parties with conflicting objectives to make it. It is assumed that in general - though not necessarily always -, a gain for a party due to a change in any dimension of the decision leads to a loss for the other party in the same dimension. We also assume the existence of a compensatory basis in the sense that some loss in one dimension may be compensated by some gain in another one. The dimensions are the clauses or attributes under discussion, and the decision to be made is the definition of the level for each attribute. Any set of values for these levels is identified as an option. We assume that the evaluation of these options by each party is made 
through a mental process of aggregation, which leads to a global value for each option. We finally assume that there is no agreement between the parties as to the level of the attributes, and a negotiator is hired to resolve the conflict. He (She) must determine in a reasonable time a set of values for the attribute levels in a way that both parties are satisfied and accept it.

\section{The AHP approach to the problem}

Let us represent the above evaluation process with the following hierarchy:

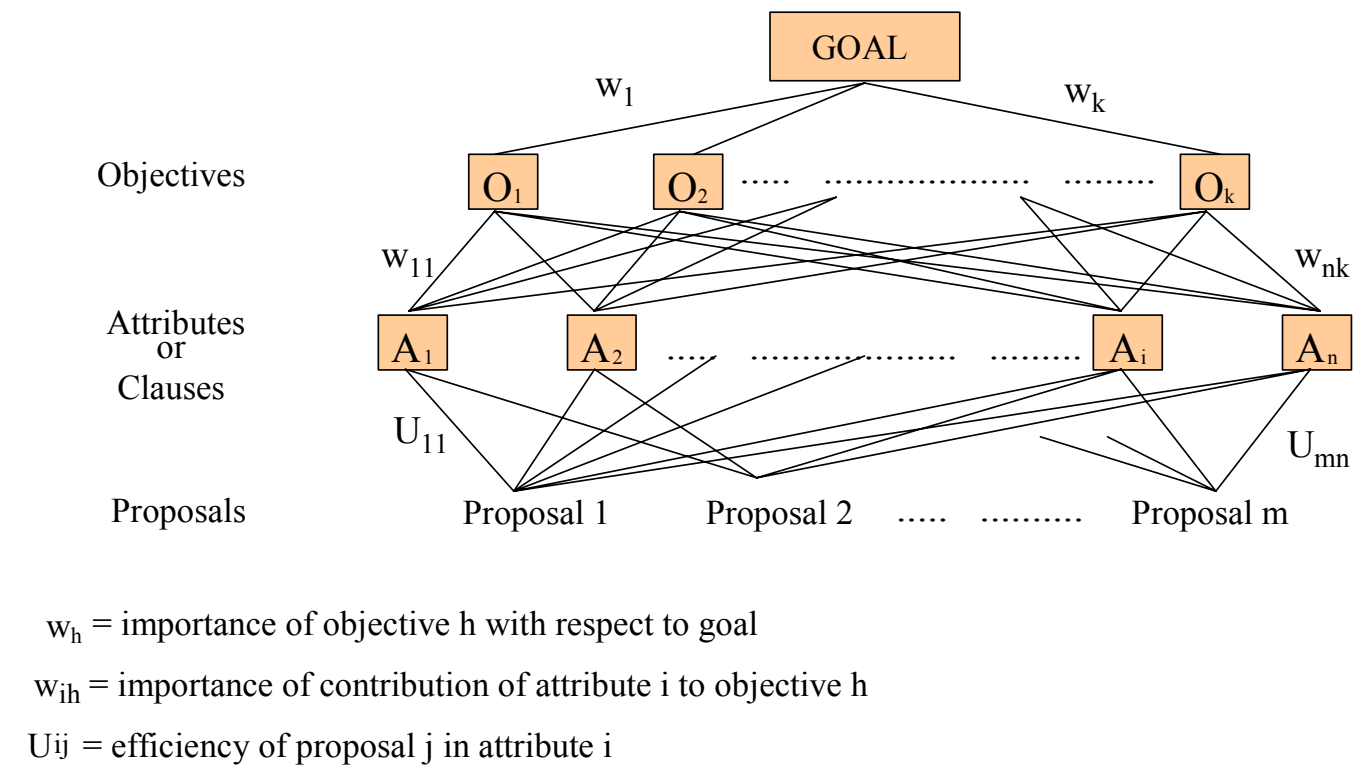

Fig. 1.- Hierarchy of the problem (for each party)

In these hierarchies the clauses or attributes will be the same for both parties, since they are the basis for the discussion. It is not so, however, for the objectives nor for the relative weights 'objectives-togoal' $\left(\mathrm{w}_{\mathrm{h}}\right)$ and 'attributes-to-objectives' $\left(\mathrm{w}_{\mathrm{ih}}\right)$, and nor for the efficiencies of the attributes in each proposal $\left(U_{i j}\right)$, which in general will not be the same for both parties. Otherwise, there would be no conflicts between them: any set of proposals would lead to the same ordering by either one, and the problem would reduce to a simple decision by one party.

Let $A_{1}, A_{2}, \ldots \ldots \ldots, A_{n}$ be the clauses or attributes, and let $x_{1}, x_{2}, \ldots \ldots \ldots, x_{n}$ be their levels. Any set of values $\mathrm{X}_{\mathrm{j}}=\left\{\mathrm{x}_{1 \mathrm{j}}, \mathrm{x}_{2 \mathrm{j}}, \ldots \ldots \ldots, \mathrm{X}_{\mathrm{nj}}\right\}$ for these levels constitutes an option or proposal. Let's call $U_{j}^{A}\left(\mathrm{X}_{\mathrm{j}}\right)$ and $U_{j}^{B}\left(\mathrm{X}_{\mathrm{j}}\right)$ the global value of proposal $\mathrm{j}$ to parties A and B respectively. We consider that each party orders the proposals based on these values, which will be the result of the mechanism of aggregation through the hierarchy above. We will assume that this process follows an additive model, which gives: 


$$
\begin{aligned}
& U_{j}^{A}\left(X_{j}\right)=\sum_{h} w_{h}^{A}\left[\sum_{i} w_{i h}^{A} U_{i j}^{A}\left(x_{i j}\right)\right] \\
& U_{j}^{B}\left(X_{j}\right)=\sum_{h} w_{h}^{B}\left[\sum_{i} w_{i h}^{B} U_{i j}^{B}\left(x_{i j}\right)\right]
\end{aligned}
$$

where

$$
\begin{aligned}
& \mathrm{x}_{\mathrm{ij}}=\text { level of attribute } \mathrm{i} \text { in proposal } \mathrm{j} \\
& w_{h}^{A}\left(w_{h}^{B}\right)=\text { importance of objective } \mathrm{h} \text { to party A (B) } \\
& w_{i h}^{A}\left(w_{i h}^{B}\right)=\text { importance of contribution of attribute } \mathrm{i} \text { to objective } \mathrm{h}, \text { in party A (B) value system } \\
& U_{i j}^{A}\left(x_{i j}\right), U_{i j}^{B}\left(x_{i j}\right)=\text { Utility (efficiency) to party A (B) of option } \mathrm{j} \text { in attribute } \mathrm{i} \text { when its level is }
\end{aligned}
$$$$
\mathrm{x}_{\mathrm{ij}} \text {. }
$$

The functions $U_{i j}^{A}\left(x_{i j}\right)$ and $U_{i j}^{B}\left(x_{i j}\right)$ may be understood as partial utility functions, and we assume that for each attribute and each party there is a function of this sort.

We also consider the existence of a total value $U_{j}\left(\mathrm{X}_{\mathrm{j}}\right)$ for every proposal $\mathrm{j}$, and define it as a weighted average of the global values $U_{j}^{A}\left(\mathrm{X}_{\mathrm{j}}\right)$ and $U_{j}^{B}\left(\mathrm{X}_{\mathrm{j}}\right)$. We have (dropping $\mathrm{X}_{\mathrm{j}}$ in the formulas):

$$
U_{j}=\lambda U_{j}^{A}+(1-\lambda) U_{j}^{B} \quad \text { for } 0<\lambda<1
$$

where $\lambda$ and $(1-\lambda)$ represent the weights of party A and party B in the decision, respectively. For equal "power" of decision, $\lambda=(1-\lambda)=1 / 2$ and the total value of the proposal will be $U_{j}=1 / 2\left[U_{j}^{A}+U_{j}^{B}\right]$.

We have assumed that there exist conflicting objectives, which eventually implies that a gain for a party due to a change in the level of any attribute leads to a loss for the other party in the same attribute. This can be viewed as opposite orientation of the partial utility function for any attribute: when it is increasing for one party it is decreasing for the other, and vice versa. Consequently, conflicts arise when a party tries to move the level of an attribute in a way to increase the value it receives from it, since this action will decrease the value for the other party.

As we said before the negotiator must determine a set of values for the $x_{i}$ 's in such a way that the resulting proposal is considered satisfactory for both parties - on the basis of the global evaluation that they make of it. This will settle the conflict.

The evaluation model, as we have said, has an additive structure. It can be shown (Raiffa, 1994) that providing that the evaluation by either party is made through an additive structure, there will be an efficient frontier of solutions. It is efficient in the sense that for any value of $\lambda$ it gives a solution (set of values for the $x_{i}$ 's) such that there are no solutions more satisfactory to both parties. Moreover, there is no solution that gives a better evaluation for one party without giving a worst evaluation to the other. In summary, for a given value of $\lambda$ any solution different to the one in the frontier is either worse for both parties or better for one and worse for the other.

Since the AHP structure of our problem has this additive property, it follows that we will have an efficient frontier of solutions, in the above sense.

\section{Determination of the efficient frontier of solutions}

Proceedings $-6^{\text {th }}$ ISAHP 2001 Berne, Switzerland 
Let $\mathbf{X}=x_{1}, x_{2}, \ldots, x_{n}$ be the vector of levels for the $\mathrm{n}$ attributes, and let $U^{A}(\mathbf{X})=U^{A}\left(x_{1}, x_{2}, \ldots, x_{n}\right)$ and $U^{B}(\mathbf{X})=U^{B}\left(x_{1}, x_{2}, \ldots, x_{n}\right)$ be the global value to parties $\mathrm{A}$ and $\mathrm{B}$ of a proposal whose attribute levels are $\mathbf{X}$. Let $U_{i}^{A}\left(x_{i}\right)$ and $U_{i}^{B}\left(x_{i}\right)$ be the partial utility to parties A and B from the attribute $\mathrm{i}$ when its level is $x_{i}$. We will have:

$$
\begin{aligned}
& U^{A}(\mathbf{X})=\sum_{h=1}^{k} w_{h}^{A}\left[\sum_{i=1}^{n} w_{i h}^{A} U_{i}^{A}\left(x_{i}\right)\right] \\
& U^{B}(\mathbf{X})=\sum_{h=1}^{k} w_{h}^{B}\left[\sum_{i=1}^{n} w_{i h}^{B} U_{i}^{B}\left(x_{i}\right)\right]
\end{aligned}
$$

where, for party A (B), $w_{h}^{A}\left(w_{h}^{B}\right)$ is the importance of objective $\mathrm{h}(\mathrm{h}=1,2, \ldots, \mathrm{k})$, and $w_{i h}^{A}\left(w_{i h}^{B}\right)$ is the importance of the contribution of attribute $i(i=1,2, \ldots ., n)$ to objective $h$.

Let $U(\mathbf{X})=\lambda U^{A}(\mathbf{X})+(1-\lambda) U^{B}(\mathbf{X})$ be the total (weighted) value of a proposal with attributes levels $\{\mathbf{X}\}$. For a given value of $\lambda(0<\lambda<1)$, we determine the set of values $\{\mathbf{X}\}$ such that $U(\mathbf{X})$ is maximum. Let's call $\mathbf{X}(\lambda)=\left[x_{1}(\lambda), x_{2}(\lambda), \ldots ., x_{n}(\lambda)\right]$ this set of values.

The efficient frontier will then be the locus of correspondent points $U^{A}[\mathbf{X}(\lambda)]$ and $U^{B}[\mathbf{X}(\lambda)]$ on the plane $U^{A}, U^{B}$.

The structure of the additive model for $U^{A}(\mathbf{X})$ and $U^{B}(\mathbf{X})$ allows us to express the equation for $U(\mathbf{X})$ as an equation of the form

$$
U(\mathbf{X})=\lambda \sum_{h=1}^{k} w_{h}^{A}\left[\sum_{i=1}^{n} w_{i h}^{A} U_{i}^{A}\left(x_{i}\right)\right]+(1-\lambda) \sum_{h=1}^{k} w_{h}^{B}\left[\sum_{i=1}^{n} w_{i h}^{B} U_{i}^{B}\left(x_{i}\right)\right]
$$

Solving the sums and grouping terms we have,

$$
U(\mathbf{X})=\sum_{i=1}^{n}\left[\lambda V_{i}^{A}\left(x_{i}\right)+(1-\lambda) V_{i}^{B}\left(x_{i}\right)\right]
$$

where $V_{i}^{A}\left(x_{i}\right)=\sum_{h=1}^{k} w_{h}^{A} w_{i h}^{A} U_{i}^{A}\left(x_{i}\right)$ and $V_{i}^{B}\left(x_{i}\right)=\sum_{h=1}^{k} w_{h}^{B} w_{i h}^{B} U_{i}^{B}\left(x_{i}\right)$ will be functions of $x_{i}$ only.

Therefore, $U(\mathbf{X})$ will be the sum of $\mathrm{n}$ functions of $\lambda$ and $x_{i}$ :

$$
U(\mathbf{X})=\sum_{i=1}^{n} \varphi_{i}\left(\lambda, x_{i}\right)
$$

where $\varphi_{i}\left(\lambda, x_{i}\right)=\lambda V_{i}^{A}\left(x_{i}\right)+(1-\lambda) V_{i}^{B}\left(x_{i}\right)$.

The maximum of the sum will be the sum of the maxima, and our problem of obtaining the maximum for $U(\mathbf{X})$ is reduced to the more simple problem of obtaining the maxima of the $\varphi_{i}\left(\lambda, x_{i}\right)$ 's.

We observe that we can define the efficient frontier using the $\mathrm{V}_{\mathrm{i}}$ 's, since 


$$
\begin{aligned}
& U^{A}(\mathbf{X})=\sum_{h=1}^{k} w_{h}^{A}\left[\sum_{i=1}^{n} w_{i h}^{A} U_{i}^{A}\left(x_{i}\right)\right]=\sum_{\mathrm{i}=1}^{\mathrm{n}} \mathrm{V}_{\mathrm{i}}^{\mathrm{A}}\left(x_{i}\right) \\
& U^{B}(\mathbf{X})=\sum_{h=1}^{k} w_{h}^{B}\left[\sum_{i=1}^{n} w_{i h}^{B} U_{i}^{B}\left(x_{i}\right)\right]=\sum_{\mathrm{i}=1}^{\mathrm{n}} \mathrm{V}_{\mathrm{i}}^{\mathrm{B}}\left(x_{i}\right)
\end{aligned}
$$

Therefore, for $\mathbf{X}=\mathbf{X}(\lambda)$ we will have the correspondent point of the efficient frontier on the plane $U^{A}, U^{B}$ :

$$
\begin{aligned}
& U^{A}[\mathbf{X}(\lambda)]=\sum_{\mathrm{i}=1}^{\mathrm{n}} \mathrm{V}_{\mathrm{i}}^{\mathrm{A}}\left[x_{i}(\lambda)\right] \\
& U^{B}[\mathbf{X}(\lambda)]=\sum_{\mathrm{i}=1}^{\mathrm{n}} \mathrm{V}_{\mathrm{i}}^{\mathrm{B}}\left[x_{i}(\lambda)\right]
\end{aligned}
$$

where $\mathbf{X}(\lambda)=\left[x_{1}(\lambda), x_{2}(\lambda), \ldots ., x_{n}(\lambda)\right]$ is the optimal vector for the particular value of $\lambda$.

There are restrictions, however, for the allowable values for the $x_{i}$ 's. Let's call $\Omega_{i}^{A}\left(\Omega_{i}^{B}\right)$ the set of acceptable values for $x_{i}(\mathrm{i}=1,2, \ldots ., \mathrm{n})$ for parties A and B respectively. The set of allowable values of $x_{i}$ for the negotiation, $\Omega_{i}$, will be the intersection of these two sets, namely $\Omega_{i}=\Omega_{i}^{A} \cap \Omega_{i}^{B}$, and the optimisation above will be subject to $x_{i} \in \Omega_{i} \forall i^{1}$.

When the $x_{i}$ 's are real variables, the acceptable values for the negotiation are usually expressed by each party as a minimum and a maximum. Let $m_{i}^{A}, M_{i}^{A}, m_{i}^{B}, M_{i}^{B} \quad(\mathrm{i}=1,2, \ldots ., \mathrm{n})$ be the minimum and maximum values for the variable $x_{i}$ for parties A and B respectively. The optimisation will then be subject to $m_{i}^{A} \leq x_{i} \leq M_{i}^{A}$ and $m_{i}^{B} \leq x_{i} \leq M_{i}^{B}$ for all $\mathrm{i}=1,2, \ldots ., \mathrm{n}$. In other words, $x_{i}$ must be in the set $\left(m_{i}^{A}, M_{i}^{A}\right) \cap\left(m_{i}^{B}, M_{i}^{B}\right)=\left(m_{i}^{*}, M_{i}^{*}\right)$, where

$$
\begin{gathered}
m_{i}^{*}=\max _{A, B}\left(m_{i}^{A}, m_{i}^{B}\right) \\
M_{i}^{*}=\min _{A, B}\left(M_{i}^{A}, M_{i}^{B}\right)
\end{gathered}
$$

Consequently, the optimisation must be subject to $m_{i}^{*} \leq x_{i} \leq M_{i}^{*} \forall i$ (See footnote 1).

Therefore, a neutral negotiator who knows the set of weights and partial utility functions of both parties may be in an exceptional position to solve the conflict. He may easily determine not only a set of proposals satisfactory to both parties but to determine the efficient frontier that may guide him in the search for some kind of optimal (or close to optimal) solution.

\footnotetext{
${ }^{1}$ It is understood that none of these sets will be empty; otherwise there will be no place for negotiation and parties will have to go to arbitration or to a court of law.
} 


\section{A simplified procedure}

The procedure as described above requires at some stage the elicitation of the partial utility functions for each attribute and each party, which in many cases is not an easy task. We propose the use of a simple straight-line approximation for each $U_{i}^{A}\left(x_{i}\right)$ and $U_{i}^{B}\left(x_{i}\right)$ as we describe next.

Let's assume, without loss of generality, that the partial utility function for attribute $\mathrm{i}$ is decreasing for party A and increasing for party B. Let $m_{i}^{A}, M_{i}^{A}, m_{i}^{B}, M_{i}^{B}$ be as before the minimum and maximum level accepted for the attribute i for each party. We may then state

$$
\begin{aligned}
& U_{i}^{A}\left(m_{i}^{A}\right)=1 ; U_{i}^{A}\left(M_{i}^{A}\right)=0 \\
& U_{i}^{B}\left(m_{i}^{B}\right)=0 ; U_{i}^{B}\left(M_{i}^{B}\right)=1
\end{aligned}
$$

For intermediate values of $x_{i}$ we have

$$
\begin{array}{ll}
U_{i}^{A}\left(x_{i}\right)=\frac{M_{i}^{A}-x_{i}}{M_{i}^{A}-m_{i}^{A}} & \text { for } m_{i}^{A} \leq x_{i} \leq M_{i}^{A} \\
U_{i}^{B}\left(x_{i}\right)=\frac{x_{i}-m_{i}^{B}}{M_{i}^{B}-m_{i}^{B}} & \text { for } m_{i}^{B} \leq x_{i} \leq M_{i}^{B}
\end{array}
$$

Using these approximations for the partial utility functions in the equations for the efficient frontier we expect to obtain solutions not far from the ones with the "true" functions.

Since the whole approach to the problem is not the search for an optimal solution - whatever this means - we can rely on these straight-line approximations in order to obtain a solution satisfactory to both parties. In the real case that we present next the optimal solution obtained with the linear approximations are very close to the one obtained with the "true" (fitted) utility functions. We show this in a Table in the Appendix, as well as comparative graphs for the efficient frontier and for some of the utility functions using both approaches.

\section{Application in a real case}

A typical case of conflict is the one that develops in the discussion of labour union contracts. It is usual to start this process with some bargaining based on the initial proposals and contra-proposals of the parties. Sometime in the process this bargaining will come to a standstill because of a handful of clauses in the contract, and as a consequence a more formal negotiation process is required. The case we now present shows ex-post (with the real actors) that the use of AHP at this stage of the process would probably have provided faster and better solutions than the standard trial and error method used in the real negotiation.

\subsection{The case $^{2}$}

By the end of 1998 the multinational venezuelan-japanese firm Honda-Mack of Venezuela, came to the end of the discussion of the labour contract with their employees. It was the result of a negotiation process between representatives of the firm and representatives of the labour union. In the last stage of the process

${ }^{2}$ Part of this case was presented by the authors in BALAS 2000 Conference at IESA, Caracas, 2000 
the negotiation was tied up mainly because of four clauses: general increase in wages, increase in the overtime rate, increase in the number of vacation days and increase in de vacation bonus. The following Table shows initial minimum and maximum negotiation levels on these clauses for each party, as well as the levels they agreed on after the usual process of proposals and counter-proposals:

\begin{tabular}{|l|c|c|c|}
\hline \multicolumn{1}{|c|}{ CLAUSES } & FIRM & $\begin{array}{c}\text { LABOUR } \\
\text { UNION }\end{array}$ & $\begin{array}{c}\text { AGREED } \\
\text { VALUES }\end{array}$ \\
\hline 1) General increase in wages & $3500-5000$ & $1500-11500$ & 4500 \\
2) Increase in overtime rates (\%) & $2-5$ & $0-5$ & 0 \\
3) Increase in number of vacation days & $1-5$ & $3-13$ & 3 \\
4) Increase in vacation bonus & $24000-34000$ & $20000-45000$ & 35000 \\
\hline
\end{tabular}

(As we can observe, in the approved contract there were some minor deviations from the restrictions in second and fourth clauses, one in favour and one in detriment of the firm position).

\subsection{The ex-post use of AHP}

A few months after the signing of the contract we proposed to representatives of both parties to perform a simulation of the negotiation process making use of AHP techniques. Besides, we emphasised that it was highly desirable to run the simulation with the same actors as the real process. We gave them a detailed explanation of the AHP technique as well as the software package we were planning to use (Expert Choice). We made them clear that we were conscious of the kind of confidential information they were going to uncover, though we emphasised it would be known only by us, but never by the other party. Both parties agreed and we conducted the process.

The AHP model was kept to a simple three level hierarchy, as follows:

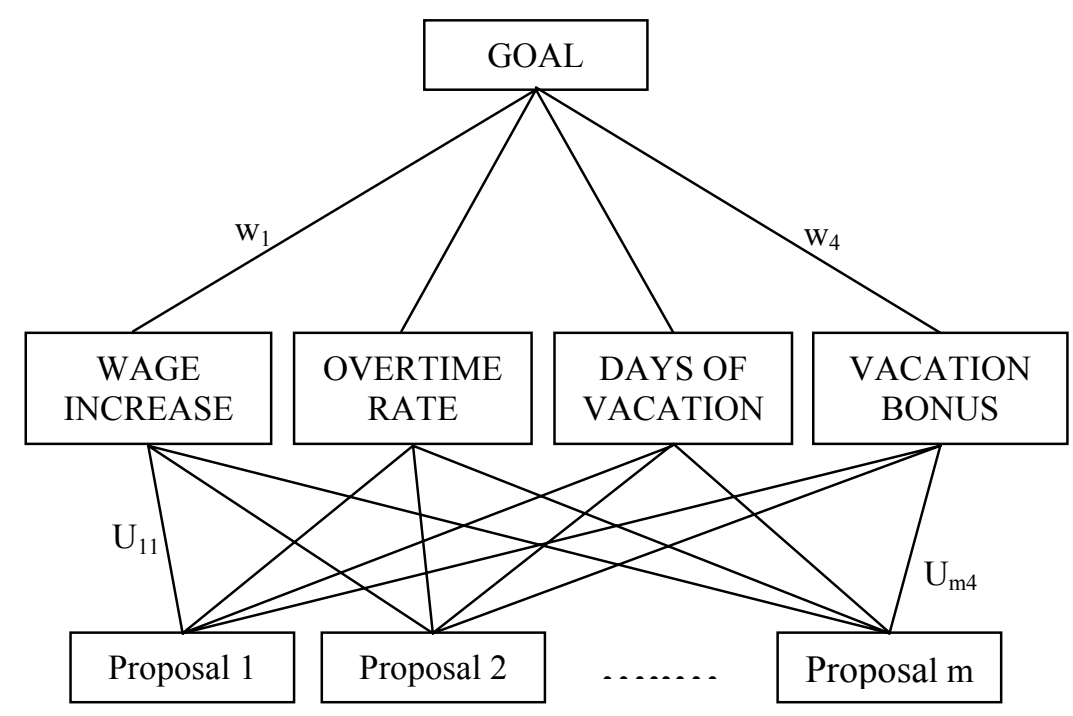

$$
\begin{gathered}
\mathrm{W}_{\mathrm{i}}=\text { importance of clause } \mathrm{i} \text { with respect to goal } \\
\mathrm{U}_{\mathrm{ij}}=\text { efficiency (utility) of proposal } \mathrm{j} \text { in clause } \mathrm{i}
\end{gathered}
$$


The $\mathrm{w}_{\mathrm{i}}$ 's were assessed, for each party, using the software Expert Choice, and the partial utility functions were assessed using the procedure suggested by Keeney and Raiffa (Keeney and Raiffa, 1976). The results of these two processes are summarised in the Appendix.

Based on those results we determined the efficient frontier and the optimal solution for several values of $\lambda$. The "optimal" levels for the clauses when $\lambda=0.50$ are shown in the following Table:

\begin{tabular}{|l|c|}
\hline \multicolumn{1}{|c|}{ CLAUSES } & "OPTIMAL" LEVELS \\
\hline 1) General increase in wages & 3500 \\
2) Increase in overtime rates (\%) & 3.2 \\
3) Increase in number of vacation days & 3 \\
4) Increase in vacation bonus & 27000 \\
\hline
\end{tabular}

These levels were used to estimate the global utility (subjective value) that each party perceives from this "optimal contract", and to estimate what we can call its "total (weighted) utility" or "total value", and we then compared those figures of merit to the ones for the approved contract. The results are in the following Table:

\begin{tabular}{|l|c|c|c|}
\hline & FIRM & $\begin{array}{c}\text { LABOUR } \\
\text { UNION }\end{array}$ & $\begin{array}{c}\text { WEIGHTED } \\
\text { TOTAL }\end{array}$ \\
\hline "OPTIMUM" & 0.814 & 0.425 & 0.620 \\
\hline CONTRACT & 0.204 & 0.374 & 0.289 \\
\hline
\end{tabular}

We observe that the so-called "optimum" is a "gain - gain" solution: both parties increased their satisfaction as compared with the approved contract. To the Firm there was an increment in perceived utility from 0.204 to 0.814 (to 0.763 with the solution based on the linear approximations to the utility functions. See Appendix), and to the Labour Union from 0.374 to 0.425 (to 0.444 in the solution with the approximations). We also observe that this effect was stronger for the Firm than for the Union.

The important issue here, however, is not whether there was a "gain" or not, since "gain" is not clearly defined in a negotiation; what matters is that both parties considered themselves more satisfied with the 'optimal' solution than with the approved contract ${ }^{3}$. Besides, this so-called optimal solution was found in a time considerably shorter than that required for an agreement in the regular negotiation process.

\section{Conclusion}

We have showed AHP to be a sound technique for the analysis and resolution of conflicts, particularly when these arouse in multiple-criteria decisions made by actors with opposing interests. A general formulation for solving the problem was developed based on AHP and multiattribute utility theory, and a simplified procedure was proposed for some of the required tasks. Finally, empirical support was provided with the use of the technique in a real case of negotiation.

\footnotetext{
${ }^{3}$ This 'optimal' solution could not be adopted, however, because the contract had already been signed and there were some legal implications in changing it. Both parties agreed in using the technology in their next negotiation.
} 


\section{Appendix}

PARTIAL UTILITY FUNCTIONS

\begin{tabular}{|l|l|l|l|}
\hline & & \multicolumn{1}{|c|}{ FIRM } & \multicolumn{1}{c|}{ LABOUR UNION } \\
\hline \multirow{2}{*}{$\mathrm{U}\left(\mathrm{x}_{1}\right)$} & "True" (fitted) & $4.281\left(10^{-7}\right) x^{2}-4.332\left(10^{-3}\right) x+10.95$ & {$\left[1.57\left(10^{-4}\right) x-0.182\right]^{-1 / 2}-0.232$} \\
\cline { 2 - 4 } & Approximation & $\frac{5000-x}{1500}$ & $\frac{x-1500}{10000}$ \\
\hline \multirow{3}{*}{$\mathrm{U}\left(\mathrm{x}_{2}\right)$} & "True" (fitted) & $-0.105 x^{2}+0.38 x+0.675$ & $(0.23 x+0.01)^{1 / 2}-0.11$ \\
\cline { 2 - 4 } & Approximation & $\frac{5-x}{3}$ & $\frac{x}{5}$ \\
\hline \multirow{2}{*}{$\mathrm{U}\left(\mathrm{x}_{3}\right)$} & "True" (fitted) & $0.068 x^{2}-0.655 x+1.58$ & $(0.125 x-0.354)^{1 / 2}-0.14$ \\
\cline { 2 - 4 } & Approximation & $\frac{5-x}{4}$ & $\frac{x-3}{10}$ \\
\hline & "True" (fitted) & $-5.017\left(10^{-3}\right) x^{2}+0.198 x-0.873$ & $(0.034 x-0.688)^{1 / 2}+0.10$ \\
\cline { 2 - 2 }$\left(\mathrm{x}_{4}\right)$ & Approximation & $\frac{34-x}{10}$ & $\frac{x-20}{25}$ \\
\hline
\end{tabular}

SOLUTIONS FOR THE CONTRACT AND THEIR GLOBAL UTILITIES

\begin{tabular}{|c|c|c|c|}
\hline & \multicolumn{2}{|c|}{ Optimal levels for the Clauses (for $\lambda=.5$ ) } & \multirow{2}{*}{$\begin{array}{c}\text { Approved } \\
\text { Contract }\end{array}$} \\
\cline { 2 - 3 } & $\begin{array}{c}\text { With "true" utility } \\
\text { functions }\end{array}$ & $\begin{array}{c}\text { With linear } \\
\text { approximations }\end{array}$ & \\
\hline Clause $\mathrm{X}_{1}$ & 3500 & 3500 & 4500 \\
\hline Clause $\mathrm{X}_{2}$ & 3.2 & 5 & 0 \\
\hline Clause $\mathrm{X}_{3}$ & 3 & 3 & 3 \\
\hline Clause $\mathrm{X}_{4}$ & 27000 & 24000 & 35000 \\
\hline $\begin{array}{c}\text { Global Utility for } \\
\text { the Firm }\end{array}$ & 0.814 & 0.763 & 0.204 \\
\hline $\begin{array}{c}\text { Global Utility for } \\
\text { Labour Union }\end{array}$ & 0.425 & 0.444 & 0.374 \\
\hline
\end{tabular}




\begin{tabular}{|c|c|c|c|}
\hline & & FIRM & LABOUR UNION \\
\hline \multirow[b]{2}{*}{$\mathrm{U}\left(\mathrm{x}_{1}\right)$} & "True" (fitted) & \multirow{2}{*}{$\begin{array}{l}4.281\left(10^{-7}\right) x^{2}-4.332\left(10^{-3}\right) x+10.95 \\
\frac{5000-x}{1500}\end{array}$} & \multirow{2}{*}{$\begin{array}{l}{\left[1.57\left(10^{-4}\right) x-0.182\right]^{-1 / 2}-0.232} \\
\frac{x-1500}{10000}\end{array}$} \\
\hline & Approximation & & \\
\hline \multirow[b]{2}{*}{$\mathrm{U}\left(\mathrm{x}_{2}\right)$} & "True" (fitted) & \multirow{2}{*}{$\begin{array}{l}-0.105 x^{2}+0.38 x+0.675 \\
\frac{5-x}{3}\end{array}$} & \multirow{2}{*}{$\begin{array}{l}(0.23 x+0.01)^{1 / 2}-0.11 \\
\frac{x}{5}\end{array}$} \\
\hline & Approximation & & \\
\hline \multirow[b]{2}{*}{$\mathrm{U}\left(\mathrm{x}_{3}\right)$} & "True" (fitted) & \multirow{2}{*}{$\begin{array}{l}0.068 x^{2}-0.655 x+1.58 \\
\frac{5-x}{4}\end{array}$} & \multirow{2}{*}{$\begin{array}{l}(0.125 x-0.354)^{1 / 2}-0.14 \\
\frac{x-3}{10}\end{array}$} \\
\hline & Approximation & & \\
\hline \multirow[b]{2}{*}{$\mathrm{U}\left(\mathrm{x}_{4}\right)$} & "True" (fitted) & \multirow{2}{*}{$\begin{array}{l}-5.017\left(10^{-3}\right) x^{2}+0.198 x-0.873 \\
\frac{34-x}{10}\end{array}$} & \multirow{2}{*}{$\begin{array}{l}(0.034 x-0.688)^{1 / 2}+0.10 \\
\frac{x-20}{25}\end{array}$} \\
\hline & Approximation & & \\
\hline
\end{tabular}

SOLUTIONS FOR THE CONTRACT AND THEIR GLOBAL VALUES

\begin{tabular}{|c|c|c|c|}
\hline \multirow{2}{*}{} & \multicolumn{2}{|c|}{ "Optimal" values (for $\lambda=.5$ ) } & \multirow{2}{*}{$\begin{array}{c}\text { Aproved } \\
\text { Contract }\end{array}$} \\
\cline { 2 - 3 } & $\begin{array}{c}\text { With "true" } \\
\text { utility functions }\end{array}$ & $\begin{array}{c}\text { With linear } \\
\text { approximation }\end{array}$ & \\
\hline Clause $\mathrm{X}_{1}$ & 3500 & 3500 & 4500 \\
\hline Clause $\mathrm{X}_{2}$ & 3.2 & 5 & 0 \\
\hline Clause $\mathrm{X}_{3}$ & 3 & 3 & 3 \\
\hline Clause $\mathrm{X}_{4}$ & 27000 & 24000 & 35000 \\
\hline \hline $\begin{array}{l}\text { Global Value for } \\
\text { the Firm }\end{array}$ & 0.814 & 0.763 & 0.204 \\
\hline $\begin{array}{l}\text { Global Value for } \\
\text { Labour Union }\end{array}$ & 0.425 & 0.444 & 0.374 \\
\hline
\end{tabular}



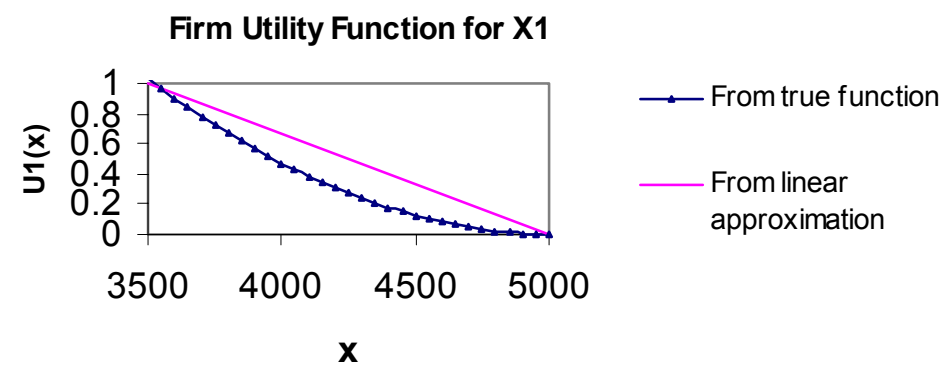

Labour Union Utility Function for X1

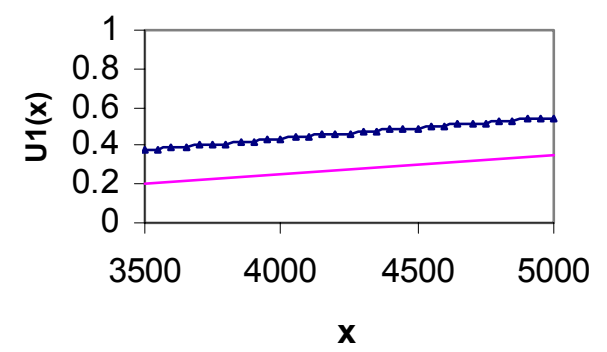

irm Utility Function for X2

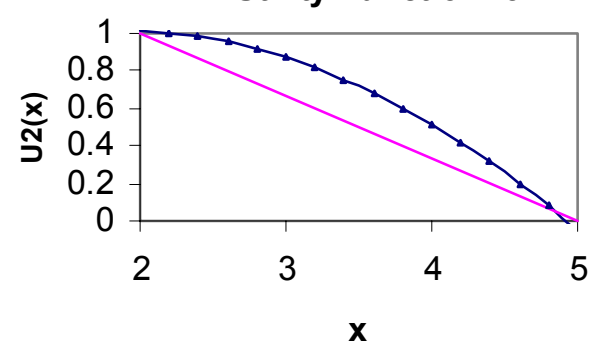

From true function

From linear approximation
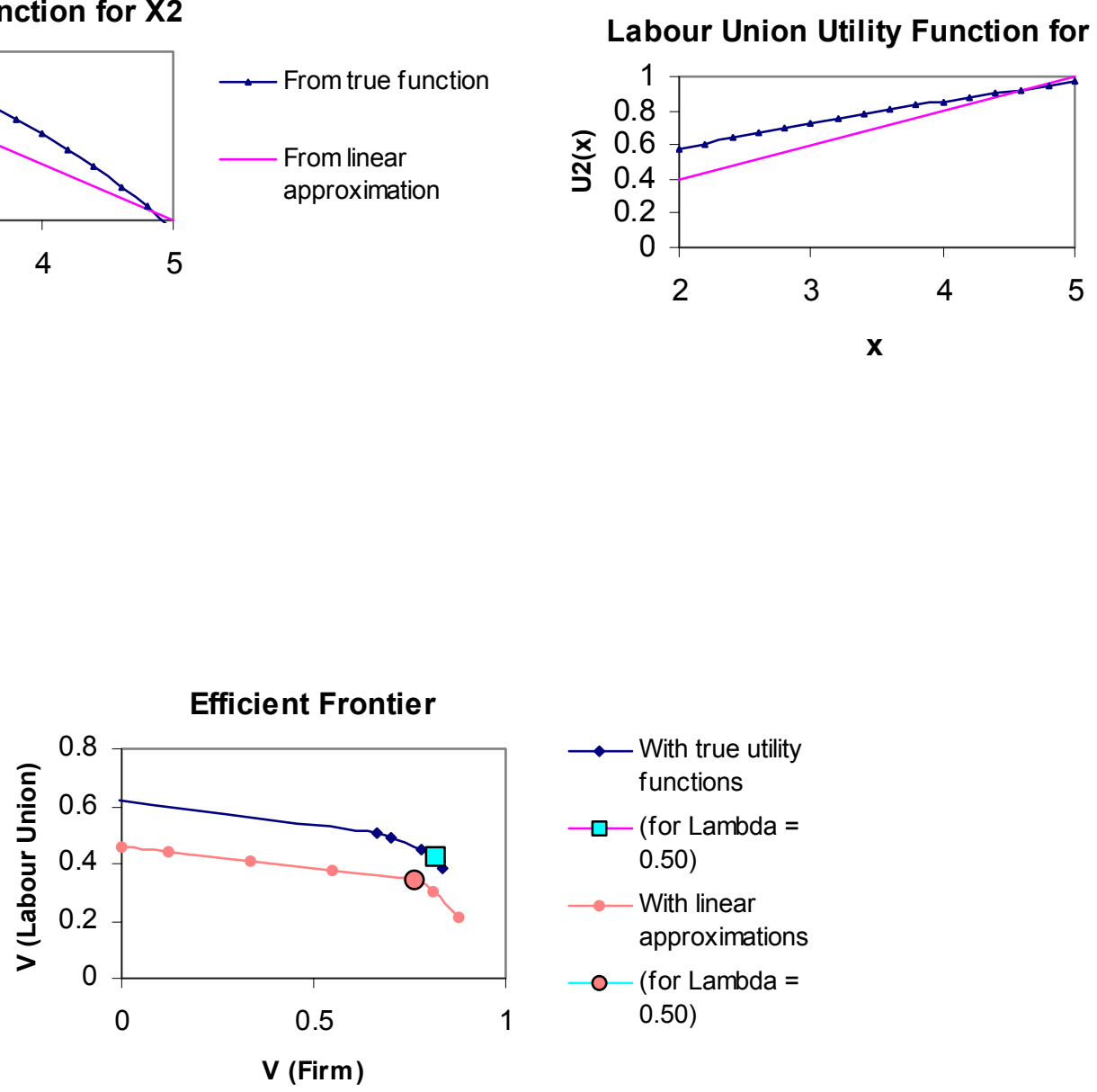
$\longrightarrow$ With true utility functions
$\square$ - (for Lambda $=$ $0.50)$
- With linear approximations
O- (for Lambda = 0.50)

\section{References}

Keeney, R. L. and H. Raiffa. (1976) Decisions with Multiple Objectives: Preference and Trade offs, New York: Wiley.

Raiffa, Howard. (1994) The Art and Science of Negotiation, Cambridge: Hardware Press (1994). 
